Shreeya Parajuli, MBBS

Department of Neurosurgery

Annapurna Neurological Institute and Allied Sciences

Maitighar, Kathmandu, Nepal

Pravesh Rajbhandari, MBBS, MS

Department of Neurosurgery

Annapurna Neurological Institute and Allied Sciences

Maitighar, Kathmandu, Nepal

Sameer Acharya, MBBS, MS

Department of Neurosurgery

Annapurna Neurological Institute and Allied Sciences

Maitighar, Kathmandu, Nepal

Basant Pant, MD, PhD

Department of Neurosurgery

Annapurna Neurological Institute and Allied Sciences

Maitighar, Kathmandu, Nepal

Address for Correspondence:

Pravesh Rajbhandari, MBBS, MS

Department of Neurosurgery

Annapurna Neurological Institute and Allied Sciences

Maitighar, Kathmandu, Nepal

Email: praveshreema@gmail.com

Received, 9 July, 2017

Accepted, 20 July, 2017

Cortical blindness is rare, but recognized complication of cerebral angiography. ${ }^{4}$ The overall incidence reported in the literature is $0.3-1 \%$ of all cerebral angiography but as high as $4 \%$ has also been reported. ${ }^{4,5}$ This incidence is slightly higher in vertebral angiography as sympathetic innervation is not as extensive or complete as that of the carotid artery system. ${ }^{4}$ Cortical blindness can occur within minutes to 12 hours after administration of contrast agent. ${ }^{7}$ Blindness after contrast enhanced CTScan head has been also reported. ${ }^{7}$ The pathophysiology is largely controversial. Contrast material penetrates blood brain barrier by opening tight capillary junction. The neurotoxocity seems to be related to chemical or ionic property amount of contrast agent as well as lipid solubility, hyperosmolality and viscosity. The adverse effect has been reported in both ionic and nonionic contrast agent. ${ }^{1,3,4,5,7}$ Besides contrast toxicity, microembolization, sudden systemic hypertension, or contrast induced hypotension, hypoxia and edema may also contribute cortical blindness after cerebral angiography. Occipital lobe is more prone to contrast agent toxicity. ${ }^{2,7}$

\section{Transient Cortical Blindness after Digital Subtraction Angiography of Cerebral Vessels}

Transient blindness following cerebral angiography is a rare but known entity. We report a case of transient cortical blindness after cerebral angiography. The patient presented with ischemic stroke and the angiography was performed to rule out carotid artery stenosis. The patient, however, gradually regained his vision over a period of 3 days. This article is to understand one of the most unusual complications that may occur while performing angiography.

Key Words: cortical blindness, digital subtraction angiography (DSA), Visual Evoked Potential 


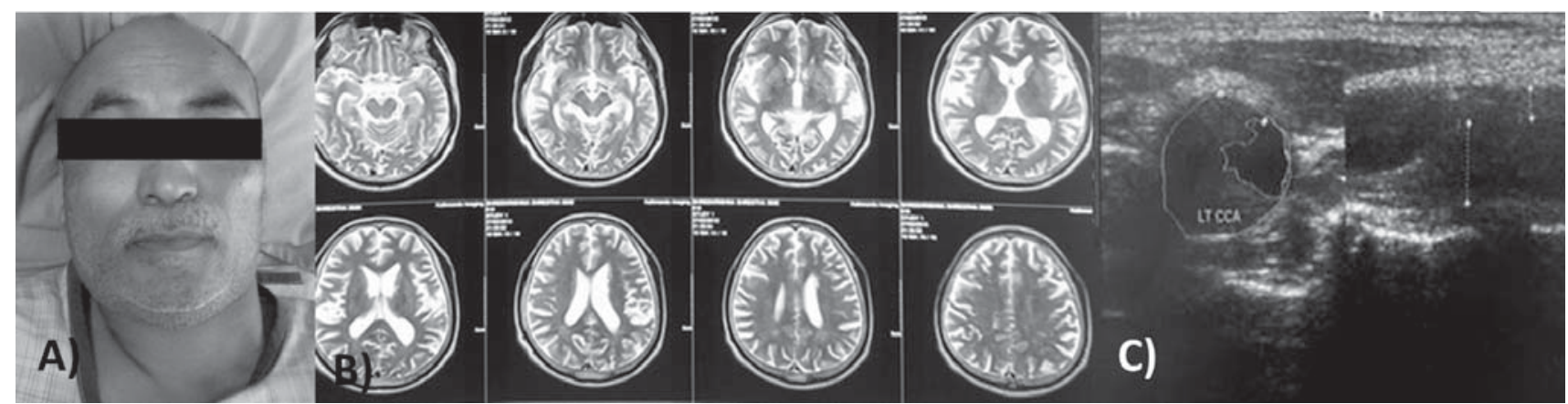

Figure 1: A) patient presented with TIA, B) MRI of same patient which is normal, C) carotid doppler of same patient showing narrowing of common carotid artery

circulation angiography. The patient was shifted to ICU as soon as the procedure was over. The patient started complaining loss of vision from the very next morning, which progressed to no perception of light by evening. However, his pupillary reflex, funds and ocular movement was normal. We thought an embolic phenomenon that could happen during angiography and his CT Scan brain was performed. CT Scan turned out to be normal (Figure 3). His Visual analysis with visual evoked potential showed low amplitude and delayed response, suggestive of low cortical activities.

The patient was treated with dexamethasone and other medications which he has been taking for hypertension and diabetes. The patient gradually started to regain his vision after 2 days following angiography. By day 7, he completely regained his vision. The patient was also fully oriented before he was discharged from hospital.

\section{Discussion}

Cortical blindness following cerebral angiography is possible complication of cerebral angiography, ${ }^{4,5,7}$ The overall incidence is $0.3-1 \%{ }^{4}$ This incidence is slightly higher in vertebral angiography due to relative lack of sympathetic innervations in the vertebrobasilar system. ${ }^{4}$ Transient cortical blindness also has been reported after contrast CT brain, Coil embolization, coronary and renal angiography. ${ }^{1,3,7,6}$ The pathophysiology behind cortical blindness is mainly due to disruption of blood brain barrier and neurotoxicity by contrast agent. , $3,4,5,6,7$ Neverthless, systemic hypertension, contrast induced hypotension, hypoxia are also responsible. ${ }^{1,5,7}$ Such cortical blindness is transient and not associated with fundus, pupillary abnormality or ophthalmoplegia. ${ }^{4}$ To the best of our knowledge, no permanent cortical blindness following cerebral angiography has been reported in the literature so far.

Beside visual loss, other symptoms such as memory disturbances, headache, vomiting, limb weakness, change of mental status and aphasia have also been described in the literature. ${ }^{1,2}$ Transient cortical blindness secondary to contrast agent have been studied with CT Scan and MRI brain. ${ }^{4,7}$ Gaurav et al. ${ }^{4}$ have shown gyriform enhancement of occipital cortex on MRI. Cortical hyperintensities also

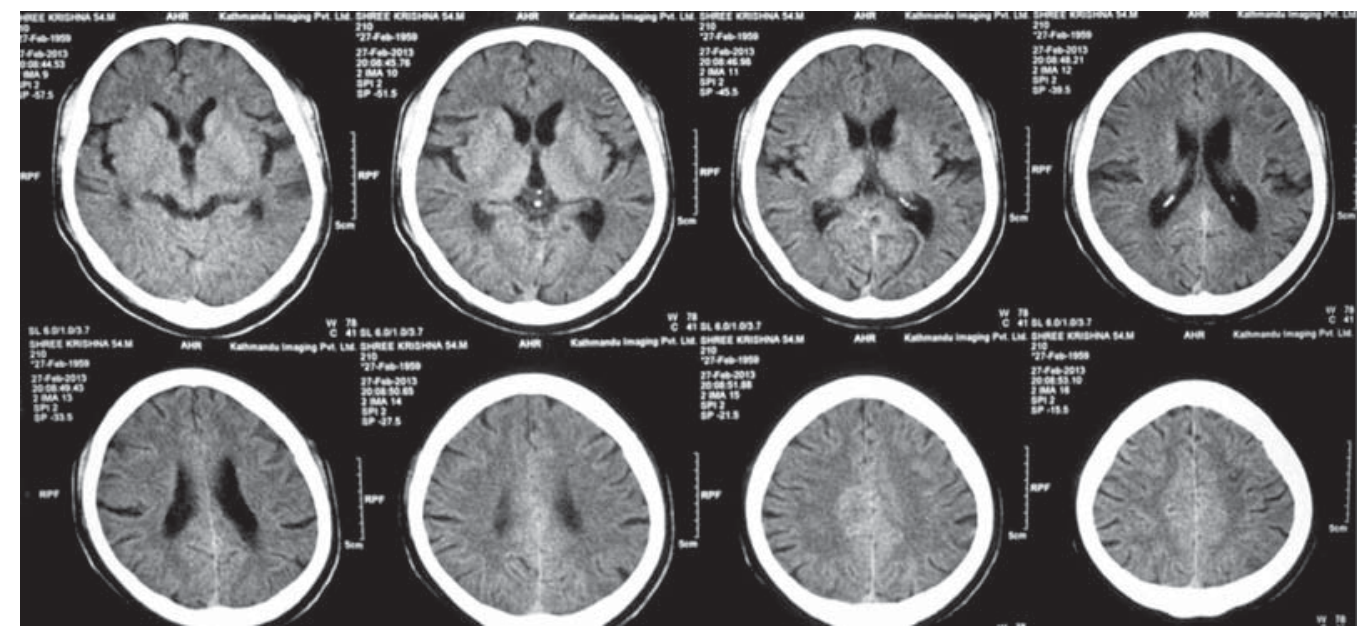

Figure 2: A) common and internal carotid artery, B) lateral view of verterbrobasilar system, C) subclavian and vertebral artery with catheter in situ 


\section{Parajuli et al}

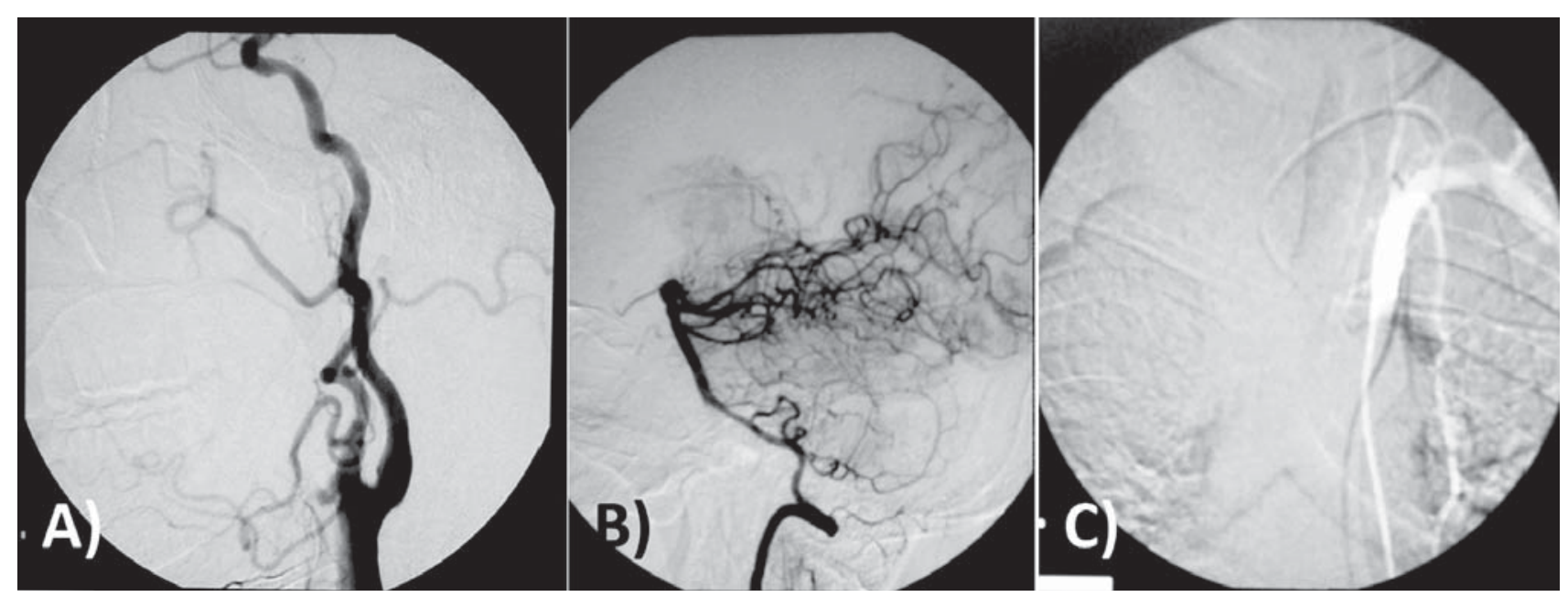

Figure 3: Post-Angiography CT Scan Head

noted on Flair sequences with restricted fluid motion on diffusion weighted images. ${ }^{4}$ He performed MRI within 6 hours of onset of visual loss. Such hyperatenuated lesions are thought to be secondary to extravasation of contrast agent after disruption of blood brain barrier. CT scan, brain, shows typical symmetrical contrast enhancement of occipital lobes, which returns to normal within 48-72 hours. Tuncer M. et al.

have reported normal $\mathrm{CT}$ brain in a patient who developed blindness after coronary angiograpgy. They performed CT scan immediately after onset of symptom. ${ }^{7}$ We performed CT scan brain after 15 hours of onset of angiography and within 3 hours of visual loss. His CT scan was apparently normal (Figure 3).

Our patient started developing visual loss almost 15 hours after angiography. His pupillary reflex, ocular movement and fundus were normal. Most of the literature has mentioned early onset of visual loss, i.e. within minutes with no other abnormalities of the pupil or fundus. 1,4,5,6 Whereas our patient developed visual loss 15 hours after the procedure and it lasted for 7 days. Hypertension or hypotension was not encountered during the procedure. The patient was treated with dexamethasone and other regular medications until he fully regained his vision.

\section{Conclusions}

Cortical blindness can occur after cerebral angiography, and is not always an embolic phenomenon. The widely accepted pathophysiology is due to leakage of contrast agent through disrupted blood brain barriers. Systemic hypertension or hypotension causing hypoxia and cerebral edema may also play a role. Even though the blindness is reversible, the radiologist, neurosurgeon, neurologist or whoever is performing the angiography, must be aware of this complication. The patient's blood pressure must be monitored during the entire procedure and dose of the contrast agent should be minimized as far as possible.

\section{Acknowledgements}

Would like to thank the staff of Operation Theater Annapurna Neurological Institute And Allied Sciences.

\section{References}

1. Clarke TR. et al. Transient cortical blindness post angiography a case report. West Indian med. J. 2011 June;60(3):357-59.

2. Horwitz N.H. and Wener L. Temporary cortical blindness following angiography. J Neurosurg. 1974 May;40:583-86.

3. Nimmi Y. et al. Cortical Blindness, Transient and Otherwise, Associated with Detachable Coil Embolization of Intracranial Aneurysms. AJNR.2008 March:29:603-607.

4. Saigala G. et al. MR Findings of cortical Blindness Following Cerebral Angiography: Is This Entity RelatedtoPosteriorReversibleLeukoencephalopathy?

AJNR Am J Neuroradiol. 2004 Feb;25:252-56.

5. Studdard WE. et al. Cortical Blindness after cerebral angiography. Case report. J Neurosurg. 1984;54:240-244.

6. S. Michael et al. Cortical blindness: Etiology, diagnosis and prognosis. Ann Neurol. 1987;21:14958 .

7. Tuncer $\mathrm{M}$ et al. Transient cortical blindness can also be seen in the absence of contrast enhancement at computed tomography scan after coronary angiography. Pak J MedApril-June 2012;28(3):54042. 